\title{
Measurement and Evolution of High-quality Development Level of Marine Fishery in China
}

\author{
LI Bo, LIU Zun \\ (Institute of Marine Sustainable Development, Liaoning Normal University, Dalian 116029, China)
}

\begin{abstract}
High-quality development of marine fisheries provides an important advantage for China to build itself into a maritime power and implement the Blue Granary Plan effectively. Based on the concepts of 'new development', 'food security', and the six dimensions of 'openness, innovation, coordination, green, sharing, and security', in this study, we established an evaluation index system for the high-quality development of China's marine fishery sector. We applied the entropy method to evaluate the high-quality development level of China's marine fishery sector from 2000 to 2016 and explored its spatial and temporal evolution rules. Our results indicated that: 1) from 2000 to 2016, China's marine fishery sector was in the primary stage of high-quality development; 2) spatially, the highquality development of marine fisheries showed an upward trend in all provinces, autonomous regions, and municipalities in the country (not including Hong Kong, Macao and Taiwan of China), and with time, the distribution pattern changed from single to multi-polarization; 3) temporally, the development level of high-quality marine fisheries fluctuated during the study period. From 2000 to 2010 , the growth rate in openness was relatively slow, but after 2010, it increased rapidly. Notably, innovation is the driving force for high-quality development. The green and security factors provide a solid guarantee for high-quality development. In the high-quality development of a region, economic development is better coordinated, and the distribution of benefits is more inclusive. This study provides a theoretical basis to formulate effective marine fishery policies for the high-quality development of the marine fishery sector in China. Exploring the high-quality development and evolution process of marine fishery is conducive to promoting the sustainable development of marine fishery industry, ensuring marine fishery food security, and alleviating global food crisis.
\end{abstract}

Keywords: marine fisheries; high-quality development; new development concept; food security; spatiotemporal evolution; comprehensive measurement

Citation: LI Bo, LIU Zun, 2022. Measurement and Evolution of High-quality Development Level of Marine Fishery in China. Chinese Geographical Science, 32(2): 251-267. https://doi.org/10.1007/s11769-022-1263-7

\section{Introduction}

According to data obtained from the Food and Agriculture Organization (FAO) of the United Nations, the global per capita consumption of aquatic products, which is one of the most important sources of protein for human beings, increases by $20 \mathrm{~kg}$ per year. The sustainable development of marine fisheries is threatened owing to the change in the global seawater environment caused by climate change, population explosion, ecological damage caused by the over-exploitation of marine resources, and predatory exploitation caused by economic development. Marine fishery, as one of the 'big agriculture', is an important source of human food. With the ever-growing population, marine fisheries and food security have become the focus of attention in not just small coastal countries but also global economies.

The Chinese economy has moved from a stage of rap-

\footnotetext{
Received date: 2021-05-10; accepted date: 2021-09-09

Foundation item: Under the auspices of the National Natural Science Foundation of China (No. 41976207, 42076222, 42071159)

Corresponding author: LI Bo. E-mail: libo_ok@126.com

(C) Science Press, Northeast Institute of Geography and Agroecology, CAS and Springer-Verlag GmbH Germany, part of Springer Nature 2022
} 
id growth to a stage of high-quality development. Highquality development is essential to maintain long-term sustainability and promote economic development, while meeting people's ever-growing need for a better life. Additionally, high-quality development is important to attain advanced stages of economic development. China is a major maritime country with abundant marine resources, and marine economy is an important part of promoting China's economic growth (Zhang et al., 2006). From 2000 to 2016, the Chinese marine economy's industrial structure was constantly overhauled ( $\mathrm{Li}$ et al., 2019).

In China, the marine fisheries development patterns are extensive, with low intensity; resource integration in the country is not perfect and simple problems, such as output value creation, excess production capacity, waste of resources, ecological damage, reasonable development resources, and adjustment of industrial structure, limit the development of marine fishery (Tong and Xia, 2017; Li et al., 2019). The high-quality development of this sector can thus realize the new era of ocean fishery economic transformation and upgradation. Therefore, studying the spatiotemporal evolution of the high-quality development of the Chinese coastal marine fishery sector, exploring the quality factors of the development of marine fisheries, and discussing its development and influencing factors are of great significance to maintain the long-term growth of marine fisheries, strengthen the food safety, and speed up the construction of marine power in China.

Foreign scholars have always paid more attention to marine fishery resources. Developed countries, such as the United States of America, the United Kingdom, and Canada, were the first to conduct research on marine fishery resource development. In general, most studies on marine fisheries mainly focus on sustainable development (Taylor et al., 2019), food security (Froese et al., 2010), the relationship between marine fishery ecological security and economic development (Koning et al., 2020), impact of climate change (Ho et al., 2020), and fishery management policies (Rosa et al., 2018). Since the beginning of 21st century, the rapid development of China's marine fishery economy has caused severe disturbances to the marine ecosystem, resulting in the vulnerability of the marine system (Li Bo et al., 2018). In late 2019, the COVID-19 pandemic had a significant impact on the industrial chain; the supply chain experienced severe disturbance and emergency health events resulted in labor shortages, logistics chain, and cold chain problems, leading to several issues, such as hike in the global market prices, lower health security, lesser livelihood security, and food security problems, which includes the vulnerability of marine fisheries. In this context, the FAO has proposed an ideal framework for addressing fisheries and aquaculture trends and challenges in a Blue Growth context'.

In the 1980s, Chinese scholars started the research on marine fisheries; these studies were mainly focused on the utilization and protection of marine fishery resources (Hu, 1980; Yang, 1980). With economic development, the exploitation of fishery resources has entered a bottleneck period, and new topics, such as the sustainable development of marine fisheries (Deng, 2000; Sun, 2003; Yan, 2009), increased fishery production (Chen et al., 2006; Zhang et al., 2009), industrial upgrading (Wang et al., 2019), oceangoing fisheries (Yang et al., 2014), recreational fisheries (Chai, 2008), carbon sink fisheries (Xu et al., 2018), and blue granaries (Yu et al., 2019), have become research hotspots. Changes in sea water structure, damage to the ecological environment, overfishing, economic diseconomy, and other phenomena have caused damage to the marine fishery system, leading to the decline of marine fishery resources and the consequences of unsustainable development.

Since the beginning of the 21 st century, the global food supply situation has been grim, and food security has become the focus of the world's attention. Marine aquatic products are an important source of proteins and guarantee food security. Food safety is not only related to population health, but also has a two-way influence with marine economic growth (economic growth promotes high-quality development of Marine fisheries to ensure food security, and food security can also promote high-quality development of Marine economy), which is one of the important evaluation standards for high-quality development. During the current situation of limited land carrying capacity (LCC), the development of marine fisheries is an important way to solve the problem of national food security, tap the development potential of the ocean, and develop the 'blue granary'. Population explosion has increased the conflicts between man and land, and the development of marine fisheries has provided a new choice for food security. To guarantee the sustainable development of 
marine fisheries and continuously provide a solid support for food security, Tang (2008) proposed the concept of 'Blue Granary' and advocated the 'China Blue Marine Food Program' to promote the construction of modern marine fishery development and sustainable science and technology support systems of marine food. Since then, studies on 'Blue Granary' have mainly focused on the development mode and construction path (Li and Han, 2019; Sun et al., 2019; Zhai et al., 2019) and science and technology innovation (Yang, 2019). After the concept of high-quality development was put forward, the academic community has initiated a new trend of combining 'blue granary' with high-quality development (Liu et al., 2017), which provides theoretical support for the development of the marine fishery economy and the improvement of peoples' livelihoods.

According to the existing literature, high-quality development has garnered the attention of academic circles; notably, the connotation and evaluation index system and the implementation of high-quality development methods have become hot research topics. However, these academic circles have not clearly defined the high-quality levels of marine fisheries development and uniform evaluation standards, and there is a lack of comprehensive evaluation of the development of Chinese marine fisheries. Marine fishery, as a branch of 'big agriculture', makes an important contribution to national food safety; therefore, safety should also be one of the evaluation standards of the high-quality development level. However, current studies on the development of marine fisheries is not high-quality, and only a few studies have explored the new concepts of food security and the development of high-quality marine fishery. In this study, we have formulated a scientific and comprehensive evaluation index system for high-quality development, according to the characteristics of the marine fisheries industry. China has a large population and it is a large maritime country. Therefore, with respect to the country's background of new normal economic development, high-quality development is the only way to encourage the long-term development of marine fisheries, which is both an opportunity and a challenge for upgrading and transforming marine fisheries. In view of this, our article embarks on the connotation of quality development in China's coastal areas. mporal evolution characteristics and influencing factors of high-quality marine fishery development were ex- plored to provide decision-making support for highquality marine fishery development in China.

\section{Materials and Methods}

\subsection{Research methods and data sources}

\subsubsection{Entropy value method}

The entropy value method is an objective weighting method that can minimize the error caused by the overlapping of information of the subjective weighting and indicators. To eliminate the dimensional difference between indicators, we adopted the range method to standardize the data used in our study (Guo, 1998; Qiao, 2004), as follows:

We selected and defined $m$ provincial units and $n$ indicators, and define $x_{i j}(i=1,2, \ldots, m ; j=1,2, \ldots, n)$ as the value of $j$ th indicator in the $i$ th province (autonomous regions and municipalities ).

Standardization of the original data using the maximum difference normalization method to analyze the original data, for the nature of the indicators ' + ' and '-', was calculated as follows:

$x_{i j}^{\prime}=\frac{x_{i j}-\min x_{i j}}{\max x_{i j}-\min x_{i j}} ; x_{i j}^{\prime}=\frac{\max x_{i j}-x_{i j}}{\max x_{i j}-\min x_{i j}}$

Then, we calculated the proportion of the $x$ sample value under the $j$ indicator to that indicator, we determined the entropy weight $\left(p_{i j}\right)$, using the equation given below:

$p_{i j}=\frac{x_{i j}}{\sum_{i=1}^{m} x_{i j}}$

The information entropy $\left(h_{j}\right)$ was calculated using the equation given below:

$h_{j}=-\frac{1}{\ln m} \sum_{i=1}^{m} p_{i j} \ln p_{i j}$

The coefficient of variance $\left(d_{j}\right)$ was calculated using the equation given below:

$d_{j}=1-h_{j}$

The specific gravity of index $\left(w_{j}\right)$ was calculated using the equation given below:

$$
w_{j}=\frac{d_{j}}{\sum_{j=1}^{n} d_{j}}
$$


Finally, we calculated the comprehensive score $\left(S_{i j}\right)$ for each indicator, using the equation given below:

$S_{i j}=w_{j} \times x_{i j}$

\subsubsection{Data source}

In this study, the study area consisted of 11 provinces, autonomous regions and municipalities along the coast of China, namely, Liaoning, Tianjin, Hebei, Shandong, Jiangsu, Shanghai, Zhejiang, Fujian, Guangdong, Guangxi, and Hainan (not including Hong Kong, Macao, and Taiwan regions of China due to unavailable data). The relevant data were derived from the Marine Statistical Yearbook from 2000 to 2016 (State Oceanic Administration, 2001-2017), Chinese Fishery Statistical Yearbook (Fisheries and Fisheries Administration Bureau of the Ministry of Agriculture, 2001-2017), and China Environment Statistical Yearbook (National Bureau of Statistics and Ministry of Environmental Protection, 2001-2017). Some missing years' data were assumed to be the average for the study period.

\subsection{Connotation of high-quality development of marine fishery and index system construction}

According to the studies on the high-quality development of the marine economy (Yang, 2018) and the development characteristics of the marine fishery industry, in this study, we defined the high-quality development of marine fisheries as follows: high-quality development in marine fishery innovation, green way for marine fishery farming and fishing activities, and simultaneous high-quality yield and efficiency of fishery production. This can ensure the safety of marine fishery ecology, production, and livelihood, from offshore to the abysmal sea, creating a three-dimensional (3D) ocean pasture, long-term stability of and guaranteed food security, and finally, achieving a state of dynamic equilibrium in an economy-society-resource system. Highquality development features effectiveness, adequacy, coordination, innovation, sustainability, sharing, and stability (Ren et al., 2017). Based on suggestions of highquality marine fishery development and the characteristics of marine fishery systems, a comprehensive evaluation index system for high-quality marine fishery development was constructed; this system provided scientific, systematic, operable, and quantitative analyses of the data obtained. The index system used in our study included five new development concepts of 'openness, innovation, coordination, greenness and sharing', and six dimensions of food security, with a total of 17 indicators. Based on the entropy method, the high-quality development level of marine fisheries in coastal provinces and cities in China was measured (Table 1).

(1) Openness dimensions: with the increase in population and the growing resource exploitation, the exploitation of fishery resources from offshore to abysmal sea has become an inevitable trend, which is also the only way to expand the national strategic resource reserve and space. Therefore, it is crucial to improve the level of opening up to the outside world, strengthen international exchanges, and promote the upgrade and optimization of the marine fishery industry to promote high-quality marine fishery development. Therefore, we chose the development level of offshore fisheries and ocean fishing boats at the end of the year to measure the opening level of oceanic fisheries in the region.

(2) Innovation dimensions: innovation is the first driving force for development, and it is the key to achieve high-quality development in marine fishery. The higher the conversion rate of innovation achievements, the more stable and resilient the industrial development, and the higher the quality of marine fishery development. Based on China's high-quality development evaluation index system (Li and Ren, 2019) and marine fishery science and technology issues in obtaining marine innovation data, we measured the innovation of marine fishery from three aspects: the number of marine scientific researchers, number of marine high-tech projects, and project funding for aquatic technology promotion organizations.

(3) Coordination dimensions: marine fishery is a compound system, and the coordinated development of three subsystems (resources, society, and economy) ensure high-quality development of this system. This study refers to the measurement index of the coordination degree of marine economy in the high-quality development of marine economy; in this study, we measured the coordination degree of marine fishery from four aspects, including the output of marine products, number of marine motor fishing boats at the end of the year, number of marine employees, and the total value of primary marine product production.

(4) Greenness dimensions: fishery resources are limited, and the ecological environment plays a decisive 
Table 1 Indicator system and weight of evaluation of high-quality development of marine fishery in China

\begin{tabular}{|c|c|c|c|}
\hline Criterion layer (weight) & Index layer & Index meaning/Measurement method & Weights \\
\hline \multirow[t]{2}{*}{ Openness $(0.1240)$} & Development level of pelagic fishery $(+)^{(1)}$ & Reflect the fishing situation of pelagic fishery ${ }^{(2)}$ & 0.0618 \\
\hline & Ocean fishing boat at the end of the year $(+)$ & Reflect the level of ocean fishing equipment & 0.0621 \\
\hline \multirow[t]{3}{*}{ Innovation $(0.1811)$} & Number of marine scientific researchers $(+)$ & Reserve force of regional marine innovative talents & 0.0653 \\
\hline & Marine fishery high-tech project $(+)$ & Regional marine related scientific research capabilities & 0.0627 \\
\hline & $\begin{array}{l}\text { Project funding for aquatic technology promotion } \\
\text { organizations }(+)\end{array}$ & Regional marine fishery research investment & 0.0531 \\
\hline \multirow[t]{4}{*}{ Coordination $(0.2364)$} & Output of seawater products output $(+)$ & Reflect the regional marine fishery production capacity & 0.0558 \\
\hline & $\begin{array}{l}\text { Number of marine motor fishing boats at the } \\
\text { end of the year }(+)\end{array}$ & Reflect regional marine fishery fishing equipment level & 0.0646 \\
\hline & Marine employees (+) & The ability of marine fishery industry to form employment & 0.0643 \\
\hline & $\begin{array}{l}\text { Gross production value of seawater primary products } \\
(+)\end{array}$ & Total output value of marine fishing and mariculture & 0.0517 \\
\hline \multirow[t]{3}{*}{ Greenness $(0.1372)$} & $\begin{array}{l}\text { Industrial wastewater discharged directly into the sea } \\
(-)\end{array}$ & Reflect sea pollution & 0.0690 \\
\hline & $\begin{array}{l}\text { Marine pollution treatment project (wastewater } \\
\text { treatment completed in the same year) }(+)\end{array}$ & $\begin{array}{l}\text { Reflect the government's environmental } \\
\text { protection of the ocean }\end{array}$ & 0.0024 \\
\hline & Per capita coastal wetland area ${ }^{(3)}(+)$ & Reflect the impact of Marine fishery on human settlements & 0.0658 \\
\hline \multirow[t]{2}{*}{ Sharing $(0.1189)$} & Per capita net income of fishermen $(+)$ & Reflect the average income level of families & 0.0652 \\
\hline & Per capita Marine aquatic product ownership ${ }^{(4)}(+)$ & $\begin{array}{l}\text { Distribution results reflecting Marine fishery development } \\
\text { results }\end{array}$ & 0.0537 \\
\hline \multirow[t]{3}{*}{ Security $(0.2024)$} & Production per unit area of mariculture ${ }^{(5)}(+)$ & $\begin{array}{l}\text { Reflect the support of Marine fishery development to } \\
\text { food security }\end{array}$ & 0.0683 \\
\hline & $\begin{array}{l}\text { Proportion of fishermen's fishery production } \\
\text { income }^{(6)}(+)\end{array}$ & $\begin{array}{l}\text { Reflects the impact of Marine fishery development on } \\
\text { fishermen's livelihood }\end{array}$ & 0.0651 \\
\hline & Economic loss from marine disasters $(-)$ & Reflects the impact of disasters on marine fisheries & 0.0690 \\
\hline
\end{tabular}

Notes: (1) The sign ' +' indicates that this indicator is a positive indicator, and the sign '-' indicates a negative indicator; (2) Dvelopment level of pelagic fishery $=$ ocean catch/ocean catch $\times 100 \%$; (3) Per capita offshore wetland area $=$ offshore wetland area/coastal population; (4) Per capita marine product ownership $=$ marine aquatic product output/coastal total population; (5) Production per unit area of mariculture = mariculture yield/mariculture area; (6) Proportion of fishermen's fishery production income $=$ fishermen's fishery income/total income of fishermen

role in the development of marine fisheries. Both ecological destruction and the deterioration of the marine environment inhibit the high-quality development of marine fisheries. Referring to the evaluation index of the marine ecological environment in the evaluation of landsea integration degree (Yang et al., 2014), we measured the green development level of marine fishery development environment from three aspects: the amount of industrial wastewater discharged directly into the sea, marine pollution treatment project (wastewater treatment completed in the same year), and per capita coastal wetland area.

(5) Sharing dimensions: high-quality development can improve the distribution system, provide people with better social, resource, and income welfare, improve the well-being of the people, enable the people to share the fruits of development, and meet their evergrowing need of a better life. Therefore, based on the connotation of high-quality sharing (Liu et al., 2020), in this study, we measured the sharing of marine fisheries from the perspective of the per capita net income of fishermen's families and per capita marine aquatic product ownership.

(6) Security dimensions: marine fisheries are an important food source and guarantee China's food security. The supply level of marine fisheries, livelihood security of fishermen, and ecological security of marine fisheries are all important factors that affect the total safety of marine fisheries. With reference to the vulnerability assessment index of food security in China (Yao et al., 2019), this study carried out migration in accordance with the development characteristics of marine fisheries. Therefore, the security of marine fisheries was measured from three aspects: yield per unit area of mariculture, proportion of fishermen's income in fishery production, and economic losses from marine disasters. 


\section{Measurement of High-quality Development Level of China's Marine Fishery}

\subsection{Spatial differentiation of high-quality develop- ment of marine fishery in China}

According to the calculation of the high-quality development level of marine fisheries in different regions from 2000 to 2016, there are obvious regional differences in the high-quality development level of marine fisheries in China (Fig. 1). We observed that over the course of the study period, the average annual development level changed from single to multi-polarization, and the order of high-quality development level of marine fishery was as follows: Shandong (0.4830), Guangdong (0.4218), Fujian (0.4224), Zhejiang (0.4060), Guangxi (0.3660), Liaoning (0.3564), Jiangsu (0.3164), Shanghai (0.3060), Tianjin (0.2658), Hainan (0.2643), and Hebei (0.2319), and the national average level of high-quality development was 0.3499 . In this study, the high-quality development level was successively di- vided into a lower development level area (comprehensive score $\leq 0.40$ ), general development level area $(0.40<$ comprehensive score $<0.55)$, and better development level area (comprehensive score $\geq 0.55$ ).

It has a big regional disparity in Chinese marine fishery. Such as Shandong, Fujian, and Zhejiang have advantaged natural resources, industrial foundation, and policy environment conditions, so that they are in good level of development in marine fishery. Therefore, the acuity can have a better market, along with the ability to resist external shocks, adjust the industrial structure, and experience high-quality early development transformation. In particular, Shandong Province attaches high importance to the development of marine fisheries and takes advantage of its superior geographical location and rich biological resources, which is why this province is ideal to start the qualitative growth transformation of marine fisheries in the country. Areas with average development levels, such as Liaoning, Guangxi, and Jiangsu, have a good foundation for industrial de-

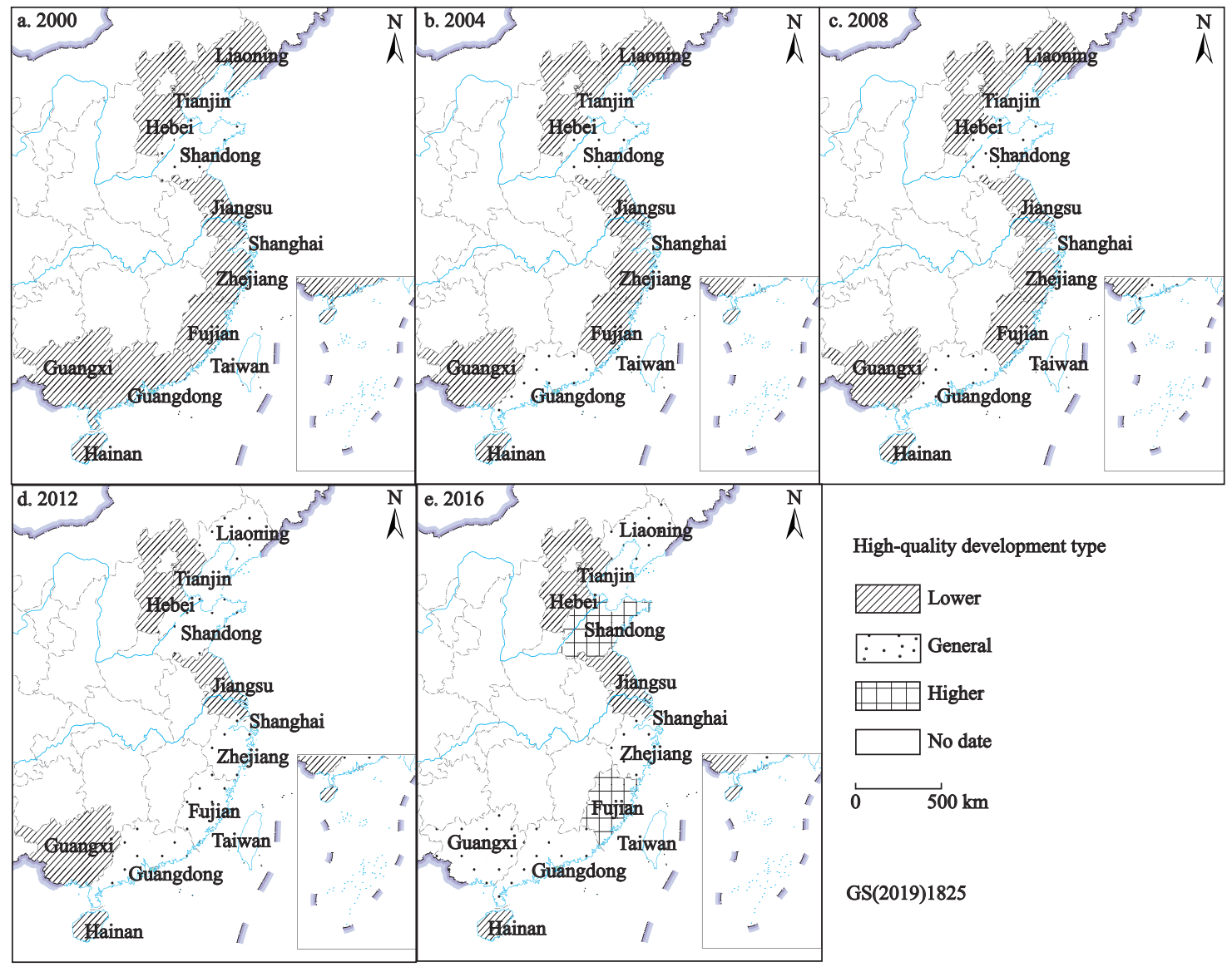

Fig. 1 High-quality development level of marine fishery in China for (a) 2000, (b) 2004, (c) 2008, (d) 2012, and (e) 2016. (Not including Hong Kong, Macao and Taiwan of China) 
velopment and relatively good natural resource conditions. However, due to insufficient policy support and a weak impetus for innovation, the high-quality development of marine fisheries in these regions is restricted. Industrial planning in Shanghai mainly focuses on the secondary and tertiary industries. Due to its special geographical location and limited space for the development of marine fisheries, marine aquaculture activities have been terminated since 2008 . Therefore, the development of high-quality marine fisheries in this region has been restricted. Areas having a lower level of highquality development, such as Tianjin and Hebei, are not conducive to the high-quality development of regional marine fisheries, due to the problems of a single industrial structure, poor resource endowment, and extensive development mode. Due to frequent natural disasters, fragile ecological systems, and backward regional production capacity, Hainan Province lags behind other coastal areas in China, in terms of high-quality marine fishery development.

In the past $17 \mathrm{yrs}$, the overall trend of high-quality marine fishery development in China has been good, but the gap between the 11 areas is still obvious. In general, the regions with higher quality of development have progressed at a fast speed, and the development mode of these regions shows a change from quantitative to qualitative growth. Although the high-quality development level of the regions having relatively low-quality development levels has been greatly improved, we found that the transformation of the quality-oriented growth model was relatively slow. From 2000 to 2016, the spatial distribution of high-quality marine fishery development in China changed from single to multi-polarization, and the overall quality development level in China improved greatly.

\subsection{Temporal evolution of China's marine fisheries}

In this study, we investigated the time evolution of the high-quality development level of marine fisheries and calculated the evaluation scores of the high-quality development of marine fisheries in 11 coastal areas. The results are shown in Table 2. During the study period, the overall development of high-quality marine fisheries showed a fluctuating growth stage.

(1) From 2000 to 2003, the high-quality development of China's marine fishery experienced stable development. Influenced by the marine fishing boom at the end of the 20th century, China's marine fishery resources have been greatly damaged, and the marine ecosystem has been destroyed. At the same time, due to the low scientific and technological level of marine fishery development and the high degree of industrial simplification, China's marine fishery development has entered a bottleneck period. In view of the sustainable utilization of resources, marine ecological damage, and other problems, China has put forward and implemented the 'zero growth' plan and 'reducing ships to produce' policy. However, owing to the lag in macro-control, the effect was not satisfactory. During this period, the overall level of high-quality marine fishery development and speed of development was slow, and the regional gap was relatively small.

(2) From 2004 to 2007, the high-quality development of China's marine fishery was in a stage of steady growth. During this period, the sustainable development of China's marine fishery was on the right track, and the policies of 'zero growth' and 'reducing ships to produce' achieved significant results. However, because of the outdated fishing equipment and lack of advanced fishery management ideas, the high quality of China's marine fishery growth speed was limited. At the same time, the differentiation between regions was gradually obvious, and a polarization phenomenon was observed in our study.

(3) The high-quality development of China's marine fishery entered a period of fluctuation from 2008 to 2013. The economic crisis in 2008 had a severe impact on the international marine fishery market. With China's entry into the World Trade Organization (WTO), the degree of integration with the international market has continuously improved. Therefore, the impact on China's marine fishery has also seriously affected the high-quality development process of China's marine fishery, resulting in this sector entering a downturn period. Meanwhile, around 2008, China's marine fishery was frequently disturbed by natural disasters, such as red tides, sea ice, and storm surges, resulting in a direct economic loss of 20.605 billion yuan from marine disasters, which is higher than the average observed for many years, leading to a sharp decline in the high-quality development level of marine fisheries. Due to the high-quality development level and strong risk resistance ability of marine fishery in Shandong Province, it maintained steady growth and earned a leading position in the mar- 
Table 2 High-quality development level of marine fishery in eleven coastal areas of China (not including Hong Kong, Macao and Taiwan of China)

\begin{tabular}{|c|c|c|c|c|c|c|c|c|c|c|c|}
\hline Year & Tianjin & Hebei & Liaoning & Shanghai & Jiangsu & Zhejiang & Fujian & Shandong & Guangdong & Guangxi & Hainan \\
\hline 2000 & 0.2261 & 0.2009 & 0.2948 & 0.2478 & 0.2977 & 0.3613 & 0.3887 & 0.4382 & 0.3442 & 0.3486 & 0.2133 \\
\hline 2001 & 0.2251 & 0.2094 & 0.3100 & 0.2369 & 0.2515 & 0.3617 & 0.3725 & 0.4123 & 0.3338 & 0.3519 & 0.2260 \\
\hline 2002 & 0.2364 & 0.2090 & 0.3199 & 0.2441 & 0.2505 & 0.3645 & 0.3775 & 0.4210 & 0.3808 & 0.3520 & 0.2192 \\
\hline 2003 & 0.2369 & 0.2054 & 0.3240 & 0.2723 & 0.2641 & 0.3844 & 0.3841 & 0.4167 & 0.3815 & 0.2875 & 0.2306 \\
\hline 2004 & 0.2460 & 0.2038 & 0.3262 & 0.2673 & 0.2905 & 0.3770 & 0.3651 & 0.4192 & 0.4017 & 0.2895 & 0.2487 \\
\hline 2005 & 0.2361 & 0.2015 & 0.3590 & 0.2855 & 0.2769 & 0.3629 & 0.3325 & 0.4432 & 0.4094 & 0.3242 & 0.2099 \\
\hline 2006 & 0.2588 & 0.2183 & 0.3338 & 0.3039 & 0.2758 & 0.3526 & 0.3399 & 0.4313 & 0.3922 & 0.3633 & 0.2577 \\
\hline 2007 & 0.2622 & 0.2181 & 0.3154 & 0.3125 & 0.3054 & 0.3761 & 0.3942 & 0.4382 & 0.4223 & 0.3483 & 0.2792 \\
\hline 2008 & 0.2574 & 0.2371 & 0.3854 & 0.2986 & 0.2878 & 0.3624 & 0.4324 & 0.4498 & 0.3439 & 0.3205 & 0.2769 \\
\hline 2009 & 0.2734 & 0.2305 & 0.3747 & 0.3056 & 0.3145 & 0.3791 & 0.3773 & 0.4636 & 0.4136 & 0.3559 & 0.2659 \\
\hline 2010 & 0.2803 & 0.2257 & 0.3789 & 0.3061 & 0.3218 & 0.4092 & 0.4159 & 0.4750 & 0.4384 & 0.3633 & 0.2737 \\
\hline 2011 & 0.2752 & 0.2333 & 0.3872 & 0.3135 & 0.3393 & 0.4273 & 0.4006 & 0.4947 & 0.4616 & 0.3749 & 0.2689 \\
\hline 2012 & 0.2922 & 0.2325 & 0.4099 & 0.3408 & 0.3588 & 0.4351 & 0.4571 & 0.5212 & 0.4813 & 0.3817 & 0.2890 \\
\hline 2013 & 0.2869 & 0.2539 & 0.3903 & 0.3451 & 0.3709 & 0.4674 & 0.4911 & 0.5634 & 0.4501 & 0.3840 & 0.2973 \\
\hline 2014 & 0.3122 & 0.2867 & 0.4262 & 0.3688 & 0.3958 & 0.4859 & 0.5233 & 0.5988 & 0.4814 & 0.3854 & 0.2976 \\
\hline 2015 & 0.3095 & 0.3102 & 0.4529 & 0.4012 & 0.3981 & 0.4953 & 0.5359 & 0.6093 & 0.5236 & 0.4108 & 0.3212 \\
\hline 2016 & 0.3043 & 0.2665 & 0.4329 & 0.3515 & 0.3792 & 0.5004 & 0.5823 & 0.6154 & 0.5199 & 0.4175 & 0.3181 \\
\hline
\end{tabular}

ine fishery sector in the country.

(4) From 2012 to 2016, the high-quality development of China's marine fishery entered a stage of rapid growth. The 12th Five-Year Plan proposed ideas for optimizing and adjusting marine fisheries, coordinating land and sea, and scientific development, which provided new ideas and approaches for the high-quality development of China's marine fishery. With the support of macro-control, China's marine fishery scientific and technological innovation capacity has been greatly enhanced, marine fishery equipment has been updated, production efficiency has been improved, ecological damage has been reduced, industrial layout has been optimized, and the 'reducing ships to produce' policy has been realized; additionally, the high-quality development of marine fisheries has been promoted to become normal. Currently, the high-quality development of marine fisheries in the 11 coastal provinces has entered the stage of rapid growth, and the overall level has achieved a qualitative leap; however, the developmental differences among the provinces have gradually become larger and the polarization phenomenon has intensified.

The initial development levels of Shandong, Fujian, Guangdong, and Zhejiang were relatively high. Around 2008, Guangdong was affected by financial crisis, and the high-quality development level of marine fisheries declined significantly. Zhejiang fluctuated under the influence of the crisis; therefore, its level declined slightly; Shandong Province maintained steady development and sustained growth. Fujian Province continued to grow, but experienced a downtrend in 2009. The average growth rate of the four provinces has been among the highest in China since 2010, and the growth level is also relatively high. From 2000 to 2008, the high-quality development level of marine fisheries in Liaoning, Jiangsu, and Shanghai was at the middle (average) level. In 2008, affected by the financial crisis, the high-quality development level of the three provinces showed a trend of regression, but after 2010, the three provinces portrayed rising volatility. High-quality development level of marine fisheries in Shanghai, Hainan, Tianjin and Hebei was low. Since 2008, mariculture activities have stopped in Shanghai, and the high-quality development of marine fisheries has been slow, but the overall trend is on the rise. Due to its short coastal zone and high degree of fragmentation, Tianjin restricts the development of marine fisheries; therefore, its fishery economy is slow and its level is far below that of the developed provinces. The development of Hainan Province fluctuated greatly from 2000 to 2008 and 
gradually developed gently after 2008. Hebei Province has always been one of the least developed provinces in the country, but with the optimization and reform of the marine fishery industry since 2012, its development speed has greatly improved. In 2016, all four provinces showed a downward trend, with Shanghai and Hebei experiencing a significant decline.

Throughout the entire study period, the high-quality development of marine fisheries showed an overall growth trend, and the growth rate showed a trend from low speed to high speed, which indicated that the highquality development of marine fisheries in China gradually stepped into the right track from the groping state.

\subsection{Overall level and dimensions of high-quality development of marine fishery}

By measuring the level of high-quality development of China's marine fishery (Fig. 2), we could deduce that the high-quality development of China's marine fishery showed an increasing trend year by year. The overall development was good, the transformation speed was fast, and the development index increased from 0.0509 in 2000 to 0.6451 in 2016.

(1) China's marine fisheries have gradually become more open. The development level of offshore fishing showed a trend of fluctuating growth; notably, the growth rate was relatively slow. The number of offshore fishing boats changed by a small amount at the end of the year, indicating that from 2004 to 2010, China established conventional marine fishery relations with Southeast Asia, the European Union, Russia, and other countries. Since 2010, China has accelerated the pace of 'outgoing' and has frequently exchanged ideas with international marine fishery economies, to expand the space for cooperation and enhance the comprehensive strength of pelagic fishery. Tianjin, Hebei, Jiangsu, Guangxi, and Hainan lagged in the opening level of marine fisheries in 2000. Since 2012, the catch amount of ocean fisheries in Tianjin has increased substantially, and the development of ocean fisheries has also greatly promoted the high-quality development level of ocean fisheries. From 2000 to 2016, the development level of China's ocean-going fishery has greatly improved, but the number of ocean-going fishing vessels has increased slightly, indicating that the improvement in the openness of China's ocean fishery is due to the improvement in the level of ocean-going technology and

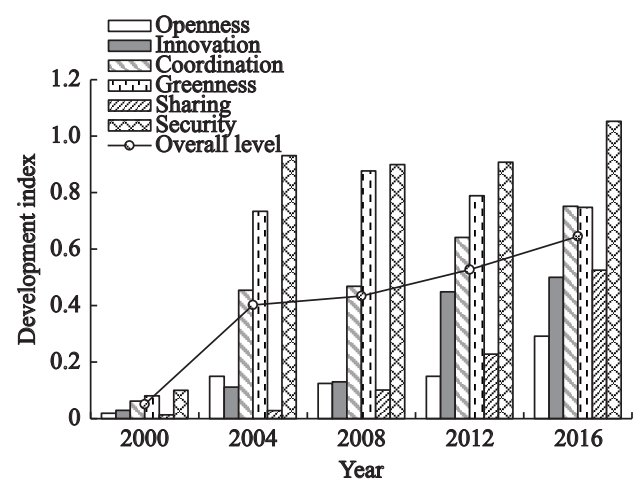

Fig. 2 High-quality development and evolution of China's marine fisheries

equipment and international cooperation. The aquatic product processing enterprises in Zhejiang, Fujian, and Shandong are concentrated and developed, the domestic and foreign markets are connected at multiple points, and the product types are rich and diverse. The rapid development of deep-sea fishing enterprises has promoted the rapid development of regional marine fisheries. Zhejiang and Shanghai are areas with a high level of opening in China. Zhejiang Province expands its opening degree year by year, and its development speed ranks first in China. The development quality of marine fisheries in Zhejiang Province has developed rapidly. After 2008, Shanghai suspended mariculture, but strengthened the international exchange of pelagic fishery and marine products, with a high degree of openness, and the status of the international exchange center is fully utilized. In recent years, the degree of integration of the marine fishery international market in $\mathrm{Ji}$ angsu Province has been low, which has a certain restraining effect on the high-quality development of the regional marine economy.

(2) The innovation level of China's marine fishery industry has increased year by year, and the innovation level is basically coordinated with the high-quality development level of marine fisheries, indicating that the scientific and technological innovation level of marine fisheries is an important driving force for the high-quality development of marine fisheries. Marine fisheries scientific research personnel and an increase in the number of marine science and technology projects, the government has also increased the fisheries technology promotion spending. Innovation dimension has a large growth, the three major indexes of innovation growth greatly improve the speed of China's marine fishery transition, but also greatly promote the development of 
high-quality Chinese marine fisheries, and innovation is increasingly becoming the core driver of high-quality development. In 2000, China's marine fishery was in the primary stage of development, and the production system of marine fishery was backward; therefore, it was urgent to upgrade and transform the development of marine fisheries. The policies introduced by local governments have resulted in marine fishery science and technology to increase the added value of marine fisheries. In 2010, China's marine fishery mariculture and fishing equipment were upgraded and optimized, application of new resources and intensive and deep processing of aquatic products were strengthened, and construction of marine fishery emerging industry was placed on the agenda, which set new requirements for the innovation of marine fisheries. Driven by these policies, the innovation of China's marine fishery has greatly improved. Due to the lack of marine infrastructure in Guangxi, Hainan, and other places, the regional economic level is backward, talent inflow is low, scientific and technological innovation ability of marine fisheries is weak, and resource elements have not been efficiently exploited, which restricts the high-quality development of marine fisheries. Lack of innovation has affected regional marine fisheries locations, such as Guangxi and Hainan, and high-quality and economic development in the future should integrate resources, speed up the implementation of science and technology, improve the quality of marine science and technology innovation, increase marine science and technology talent training and capital investment, use scientific and technological achievements to drive marine technical improvement of traditional industry, and accelerate the marine science and technology transformation. At the same time, we should promote and build innovation platforms for universities and research institutes, improve the mechanism for intellectual property rights (IPR) protection, promote the common development of talents of all kinds and their intellectual achievements, and assist in the high-quality development of marine fisheries.

(3) In terms of the coordination degree of China's marine fishery economic development, the high-quality development level of China's marine fishery increased steadily from 2000 to 2008 , but declined slightly after 2008. Notably, the impact of the financial crisis and the adjustment of the national marine economic industrial structure have affected the funds and policy tilt of the marine fishery industry. The proportion of gross marine fishery products in the gross marine economic product decreased from $50.43 \%$ in 2000 to $7.27 \%$ in 2016 . Although the overall development level of marine fishery increased, the growth rate of the production of seawater products, number of fishing boats, and output value of marine primary products decreased, resulting in a small decline in coordination. Under the guidance of the policy of 'reducing boats to produce', the ownership of marine motor fishing boats decreased at the end of the year, but with the improvement of aquaculture technology, the production of mariculture increased year by year. In recent years, the development of the aquatic processing industry, number of aquatic processing categories, and quality of marine fishery production has increased rapidly. In addition, the government has adjusted the structure of seawater products through macrocontrol and developed aquatic products that have more economic value. The output value of marine fishery primary products has maintained a steady growth trend. At the same time, the development of marine fishery secondary and tertiary industries will also provide more jobs. Marine fisheries will coordinate the transfer of fishermen to other industries and promote the upgrading and optimization of marine fishery industrial structures. In 2016, the economic income of marine fisheries in Liaoning Province ranked fourth in China, but the primary processing industry accounted for a large proportion. Therefore, the economic growth of marine fisheries was constrained, and the transformation speed of high-quality marine fishery development was relatively slow. In Hebei and Tianjin, because of insufficient resource endowment, short coastline, and insufficient sea space suitable for fishery cultivation, the production of marine fisheries mainly relies on fishing and whether the species of mariculture is single, economic development of marine fishery is unbalanced, and there is no reasonable policy support; therefore, the high-quality development level of marine fishery is relatively low. Marine economy coordinated development is an important guarantee to realize high-quality marine economy development of the marine economy development coordination relationship (Di et al., 2019), development in the future should considered the sea, establish and perfect the space marine fisheries development planning, establish the resources on land or sea, account different 
industry, and space elements, such as coordinates, to build a new pattern. To improve the quality of employees, future studies may adjust and upgrade the structure of the marine fishery industry, improve the technical and equipment level of marine fishing boats, and promote the coordinated development of marine fisheries.

(4) Because of the early 21 st century Chinese marine fishery development mode is more extensive, serious environmental damage, the ' 21 st century agenda' implementing sustainable development plan is put forward. Therefore, after 2000, the development of Chinese marine fishery green level gradually improved. However, from 2008 to 2016, the green development level of marine fisheries fell. The number of marine pollution control projects has remained stable. However, due to the agglomeration of population and industries in the eastern coastal areas, the per capita wetland area has shrunk, coastal ecological environment has been continuously damaged, and ecological pressure has been increasing, resulting in a downward trend in the green development level of marine fisheries since 2008.

(5) There has been a qualitative leap forward in the sharing of marine fisheries in China. In the past 20 years, China's marine economy has been developing rapidly. The purpose of economic development has always been to improve peoples' well-being, and the fruits of development have always been shared by the people. With the development of marine fisheries, the distribution system of marine fisheries is becoming more and more ideal, and the sharing of China's marine fishery has greatly increased from 0.0135 to 0.5255 , indicating that peoples' livelihoods have been continuously improved, social distribution has become more equitable, and the development achievements of marine fisheries have been widely benefited as well. The achievements of high-quality marine fishery development are mainly reflected in the exponential growth of the per capita net income of fishermen, and high-quality development has greatly improved the living standards of the fishermen. The amount of aquatic products per capita is also gradually increasing, and the development of marine fisheries has provided food and nutrition for more people. Guangxi and Shanghai, due to their small population base and high per capita net income, are among the best in terms of sharing. Due to the problems of regional marine fishery economic development in Hebei Province and the large population in
Guangdong Province and the large gap between the rich and the poor, sharing in these two provinces is lower than that observed in other provinces and cities. Over the past 17 years, the per capita net income of fishermen's families and the per capita ownership of marine aquatic products have increased year by year, and the high-quality development of marine fisheries has greatly improved the livelihood of fishermen. To improve people's livelihoods, we should accelerate the optimization of the distribution mechanism and improve the livelihood and production subsidies of fishermen, so as to ensure that the high-quality development of marine fishery benefits people and improves peoples' well-being.

(6) At the same time, the extensive development mode leads to the low output value of marine fisheries, and the unsustainable development and short industrial chain lead to a low supply of marine fishery, which cannot guarantee long-term food security of marine fisheries. To solve these problems, at the beginning of this century, China adhered to the implementation of sustainable development and the 'blue granary' strategy, greatly improving the safety of China's Marine fishery, building a solid defense line for national food security. In 2000, owing to the initial stage of economic development and backward equipment, the output was low. However, after 2000, China's marine fishery development level developed rapidly, mariculture production efficiency was improved. China's grain structure was enriched, better nutrition sources were provided for the people, and food security was maintained. The decrease in the proportion of fishermen's income from fishery production indicates that the income sources of fishermen were more diversified, and the risk resistance of the fishermen's families improved, which greatly guarantees the livelihood safety of fishermen. The income of fishermen was stable and diversified, the resistance to marine disasters was stronger, and China's marine and fishery food security was effectively guaranteed, resulting in outstanding contributions to sharing the pressure on land food resources. At present, the marine fishery food security in all provinces in China are rapidly improving, which provides a 'protective umbrella' for the high-quality development of China's marine fishery.

\subsection{Extension of marine fishery industry chain pro- motes high-quality development of the industry}

Evidently, to promote the reform of marine fisheries 
supply side, and to improve marine fishery comprehensive benefits and international competitiveness are the main goal of high-quality marine fishery development in the future. In this study, the upstream, middle, and downstream of the marine fishery industry chain were divided into three stages: 'breeding and fishing', 'processing and circulation', and 'application and consumption', as shown in Fig. 3. The high-quality development path was analyzed according to the development characteristics of each link of the industrial chain. Therefore, based on the analysis of the status quo of the development of various dimensions of the industry, this article adds thinking about each link of the industrial chain in order to promote the high-quality development of marine fisheries while seeking stability.

(1) The upstream stage of the marine fishery industry chain, aquaculture, and fishing is an important basis for the high-quality development of marine fisheries. However, marine fishery aquaculture and fishing in China have problems of low added value, low economic value, and imbalance between supply and demand. At the beginning of the 21 st century, China's marine fishery developed rapidly, and the marine fishery breeding and fishing industry developed rapidly as well. In pursuit of the output, the requirements for economic value and product quality were not high. With the transformation of qualitative growth, the output of economically valuable aquatic products, such as crustaceans, shellfish, and algae, increases annually, and the output value and output of marine fisheries increase rapidly as well, thus, improving the coordination of marine fishery development. The 'zero growth' plan achieved remarkable results. In 2000, the fish output of marine products of China was about 1032.14 million $t$, and in 2016, the fish output was about $10361300 \mathrm{t}$, with a small increase, indicating that marine fisheries are striving to maintain a sustainable development trend. At the same time, deepsea fishing from 2000 in $865200 \mathrm{t}$ up to 2.192 million $\mathrm{t}$ the development of ocean fishery effectively enhance food safety level; at the same time fishing is also involved in the sale and purchase of local trade activities, it also shortens the fishing companies in China and overseas market and promotes the development of marine fishery in high-quality.

(2) The midstream of the marine fishery industry chain processing and circulation are not only important links for increasing the added value of marine fishery products, but also a key link for integrating the primary, secondary, and tertiary industries. China has long been based on rough processing; high-quality fresh packaging, quick-frozen fresh, pickling, and freeze-drying are the most common processing technologies. With the development of the social economy and the further opening of the international market, the market has

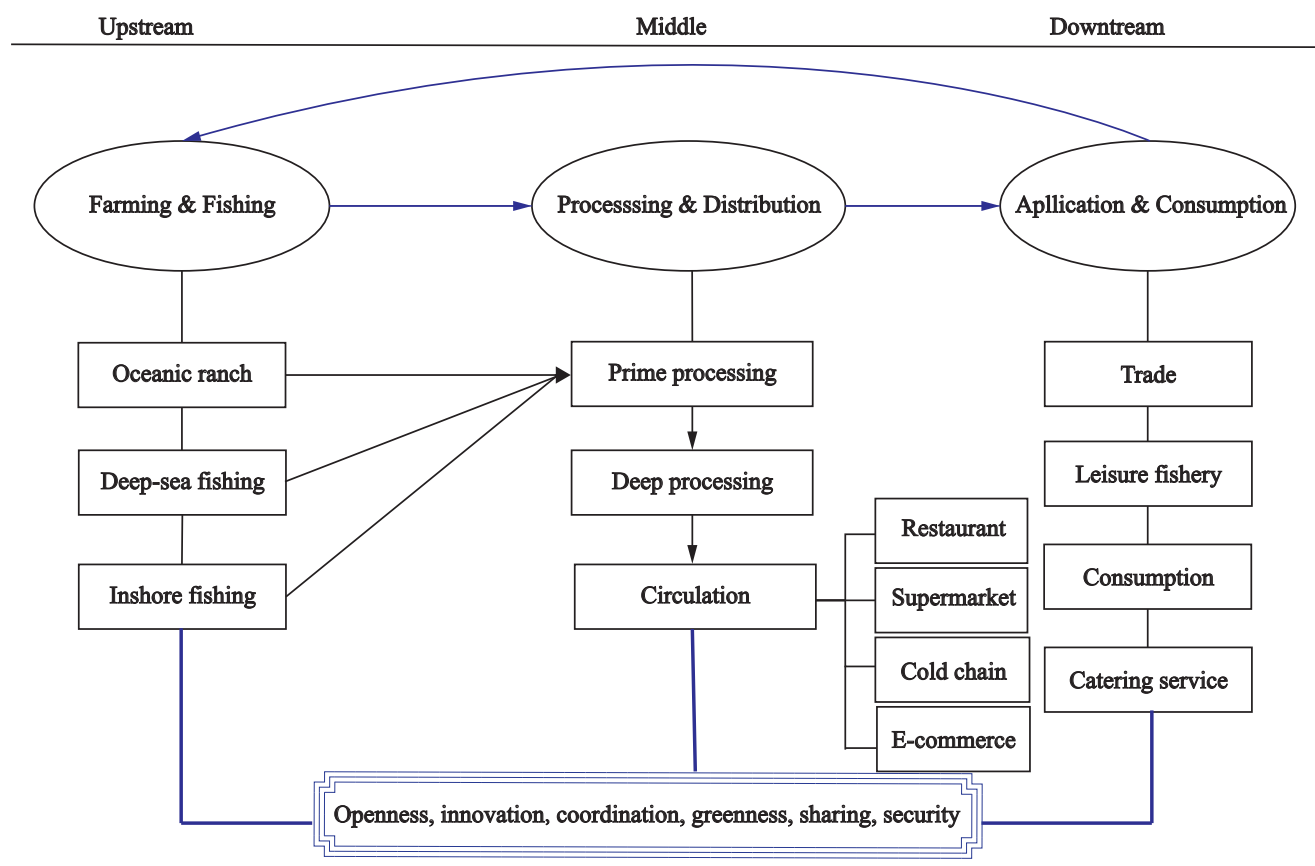

Fig. 3 Marine fishery industry chain 
higher requirements for China's aquatic product processing industry; therefore, China's aquatic product processing industry faces more severe challenges in processing water technology, equipment optimization, and product quality. Thus, to promote the quality growth of marine fisheries and break the bottleneck of marine fishery development, it is urgent to optimize the industrial structure of marine fisheries. Notably, the output value of the marine fishery and construction industries increased from 267.964 billion yuan in 2008 to 566.662 billion yuan in 2016, while the output value of the fishery circulation and service industry increased from 282.811 billion yuan in 2008 to 678.076 billion yuan in 2016. China's marine fishery secondary and tertiary industries are developing rapidly, and structural reform has achieved initial results. Furthermore, the marine fishery processing industry is developing rapidly with the transformation of quality-oriented growth. In 2016, the total amount of seawater-processed products reached 17.7507 million $t$, an increase of more than 6.08 million t compared with the output of 2008; the output of refined and deep-processed products increased significantly. At the same time, with the growing per capita income, consumers for deep processing of high nutritional value and water product demand increased, but by 2016, the number of processing enterprises of aquatic products processing enterprises above the designated size was less than $30 \%$. Therefore, the reform of the demand side also reversed the transmission supply side, seafood market demand reversed transmission aquaculture industry reform, there was high demand for deep processing products, and unequal product supply capacity restricted the high-quality development of the whole marine fishery industry. Therefore, starting from both ends of the industrial chain, accelerating the integration of supply side reform and demand-side management is another important path for promoting the highquality development of marine fisheries.

(3) The downstream stage of the marine fishery industry chain application and consumption stage is the final stage of product value realization. The improvement of peoples' living standards required a healthier, more nutritious, and more convenient diet; therefore, more aquatic products flowed into the market and were sold in major supermarkets and catering institutions. Rapid development from a global perspective, marine fisheries, with the development of the Internet of Things and ice fresh technology innovation, high-end aquaculture have started to enter the Chinese view. The domestic market for high-end consumption of aquatic products demand is huge, but the current high-end products for marine fisheries production in China are less, and the supply gap is large. Compared with imported high-end aquatic products, rough-processed products are still the main products in China's international trade market, and few high-end products form brands circulate in the international market. Second, with the rapid development of the Internet, e-commerce has become a new highland for aquatic consumption, which also drives the development of cold chain storage and promotes the integrated development of secondary and tertiary industries. Many e-commerce platforms also provide more sources of income for small fishing enterprises and fishermen, shorten the distance between the place of origin and consumers, save costs, effectively increase income, and guarantee the livelihood of fishermen. Third, in recent years, recreational fishing booms have increased, along with integrated traditional fishing methods, fishing gear, fishing resources, and natural resources with the local cultural environment, developing local tourism, and enhancing fishing cultural experience to improve fishermen's income and enrich consumers consumption experience (Liu, 2003). As an organic combination of marine fishery and leisure tourism, recreational fishery has become an important target of marine fishery industrial structure adjustment, owing to its advantages of green development, high coordination degree, and outstanding output value.

\section{Discussion}

Since 2002, China has become the world's largest exporter of aquatic products. According to statistics from the FAO, China contributed $62 \%$ to the world's production of farmed food fish in 2015, more than half of the world's demand (FAO, 2017). In recent years, China has become the world's third largest importer of fish products, with a per capita apparent production of 37.9 $\mathrm{kg} / \mathrm{yr}$, up from $31.9 \mathrm{~kg} / \mathrm{yr}$ in 2009 (FAO, 2017). In 2008, China implemented a plan to reduce the number of boats in production, and updated the equipment of fishing boats, with a view to gradually realize the coordination between the fishing intensity of the ocean and its resource carrying capacity. At the same time, the 
fishing sector provided more than 14 million jobs in China, and these new jobs have helped improve peoples' livelihoods. Relevant data of China's marine fishery retrospective analysis shows that since 2000, China has been committed to the development of the marine fishery quality and protection of its marine fisheries food security and has made a great success in the high-quality development of China's marine fishery.

Traditional marine fisheries studies mainly focus on the sustainable development of marine fisheries or they regard food security as the purpose and reason for marine fishery resource conservation (Huang et al., 2018), and the relationship between fish and food security is multifaceted and complex (Fabinyi et al., 2017). The food security problem of marine fisheries also restricts the its high-quality development. Therefore, studies on the measurement of the level of high-quality development of marine fisheries need to consider food security. Notably, few studies focus on food security and its relationship with the development of the marine fishery quality, ignoring the fishermen's livelihoods and food security for the development of marine fishery quality. Based on this, our study integrates the new development concept with the food security strategy to pursue a more comprehensive measurement and evaluates the high-quality development of China's marine fishery.

Our results indicated that the high-quality development level of marine fisheries in China has gradually improved, and its spatial differentiation is significant. Due to the influence of resource conditions, innovation level, local policies, and other factors, the high-quality development level of marine fisheries in different provinces is gradually increasing, which is contrary to the 'coordinated development strategy'. However, our study on the coordinated development of Marine fishery is limited to the coordination of 'marine fishery' comprehensive benefit subsystem, regional land-sea coordination, as well as the coordination of fishery and other marine industries (Pauly et al., 2005; Du, 2015; Keithly and Roberts, 2017; Huo et al., 2020). Further studies are needed to improve the distribution mechanism of the benefits of marine fishery development.

We found that policy guidance has a significant positive impact on the high-quality development of marine fisheries. Policy generally drives marine fishery resource management from the top down, and also directly affects the fishermen's livelihoods. Since 2010, the marine economy has attracted attention in China and has started to shift to quality-oriented growth. Therefore, since 2010, the development level of China's marine fishery has greatly improved, and the quality of growth has also greatly changed. From this, it can be seen that the policy changes to the development of marine fisheries are intuitive and powerful. However, in addition to national macro-policy regulation, local governance and financial incentive mechanisms can better promote the high-quality development of regional marine fisheries. Shandong Province has issued the ' 18 Opinions on Promoting the High-quality Development of Marine Fishery', thus, increasing the level of high-quality development of marine fishery and taking a leading position in the country. Therefore, we could deduce that the highquality development of marine fisheries requires not only macro-control, but also cross-sectoral connections between local management and national institutions (Gelcich et al., 2010).

The overall development of land and sea determines the level of regional marine fishery economic development. The development of land and sea industries is interconnected, creating a seaward economy and strengthening the land-sea linkage, thus, extending the industrial development chain of marine fisheries. Scientific and technological input can improve the resilience of the marine fishery economy, change the single industrial structure, and guarantee the safety of fisheries.

According to the data calculated in this study, the high-quality development of China's marine fisheries has shown initial effective results, indicating that China's effective fishery management policies have made outstanding contributions to improving the efficiency and sustainability of marine fishery economic development. At present, the sustainable development and food security of marine fisheries are still hot issues in the world. Some developing countries that rely on marine fisheries for a living are urgently needed for the transformation of marine fisheries development and need the support of the international community, to ensure regional food security and the livelihood security of small-scale food producers. As the largest developing country, China can provide development inspiration and fishery management support to other developing countries that are experiencing similar national conditions, thus, providing theoretical support for poverty alleviation, economic growth, food security, and sustainable development of 
global marine fisheries.

Due to the influence of data availability, we could not obtain microscopic data of marine fisheries and data from other related marine industries. Therefore, we could not conduct an in-depth analysis of the high-quality development of marine fisheries in a small area. At the same time, because the ocean is a complex multi-dimensional system, it is not feasible to completely strip off a single industry for separate analysis, and therefore, it is impossible to analyze the coordinated development of marine fisheries and other industries. Further research on the high-quality development of marine fisheries also requires more detailed marine fishery monitoring data, along with other industrial development data.

\section{Conclusions}

In this study, the context of high-quality development of China's marine fishery was defined. Based on the connotation of 'new development concept' and 'food security', the evaluation index system of high-quality development of marine fishery in six dimensions was constructed, including "openness, innovation, coordination, green, sharing, and security." The entropy method was used to measure the development level of high-quality marine fishery, and the temporal and spatial evolution law of high-quality Marine fishery development in China from 2000 to 2016 was revealed. Additionally, we analyzed the high-quality development of the marine fishery industry chain; the conclusions of our study are as follows:

(1) From 2000 to 2016, the high-quality development level of China's marine fishery increased year by year, with a good momentum of overall development, and the differences in high-quality development levels among different regions gradually increased, resulting in regional imbalance.

(2) Spatially, China's marine fishery developed from 'one province alone' to 'high in the south and low in the north'. The high-quality development levels in Shandong and Guangdong in central China were much higher than those in other provinces and cities, while Hebei and Tianjin were relatively backward.

(3) Temporally, the development of Chinese marine fishery quality portrayed fluctuating growth during 2000-2010. The level of development of Chinese marine fishery quality was lower, with slower growth in
2008, global financial crisis, natural disasters, but the development of Chinese marine fishery quality levels rapidly increased after 2010 .

(4) From 2000 to 2016, the six dimensions of China's marine fishery have all improved, and all the dimensions of 11 coastal areas in China have also improved. However, there is still room for improvement in green production, fishermen's welfare, and scientific and technological innovation.

(5) From the perspective of the industrial chain, the added value of China's marine fishery industry chain is low. Although China's marine fishery has developed rapidly since 2000 , it can be further developed, owing to a large market demand for intensive and deep processing products. The international market remains to be developed as well. The analysis of each link of the industrial chain shows that five development concepts run through it, and high-quality development of marine fishery is a strong guarantee for marine fishery food security.

\section{References}

Chai Shousheng, 2008. Theory and Practice: A Study on the Development of the Leisure Fishery. Qingdao: Ocean University of China. (in Chinese)

Chen Liqun, Zhang Zhaohui, Wang Zongling, 2006. A model for marine fishery resources sustainable utilization: marine ranching. Coastal Engineering, 25(4): 71-76. (in Chinese)

Deng Jingyao, 2000. Marine fisheries resources conservation and sustainable utilization. Chinese Fisheries Economics, 6: 21-22. (in Chinese)

Di Qianbin, Yu Zhe, Xu Lixiang, 2019. Spatial-temporal coordination mode of marine economic development under the background of high-quality growth: based on the empirical study of prefecture-level cities in Circum-Bohai Sea. Scientia Geographica Sinica, 39(10): 1621-1630. (in Chinese)

Du Linan, 2015. The Research on the Correlation and Factors Efficiency Evaluation of Marine and Terrestrial Industries. Dalian: Dalian Maritime University. (in Chinese)

Fabinyi M, Dressler W H, Pido M D, 2017. Fish, trade and food security: moving beyond 'availability' discourse in marine conservation. Human Ecology, 45(2): 177-188. doi: 10.1007/ S10745-016-9874-1

FAO (The Food and Agriculture Organization), 2017. Fishery and Aquaculture Country Profiles: China. Rome: FAO. Available at : https://www.fao.org/fishery/en/facp/chn?lang=en

Fisheries and Fisheries Administration Bureau of the Ministry of Agriculture, 2002-2016. China Fisheries Statistical Yearbook (2001-2015). Beijing: China Agriculture Press. (in Chinese) 
Froese R, Branch T A, Proelß A et al., 2011. Generic harvest control rules for European fisheries. Fish and Fisheries, 12(3): 340-351. doi: 10.1111/j.1467-2979.2010.00387

xGelcich S, Hughes T P, Olsson P et al., 2010. Navigating transformations in governance of Chilean marine coastal resources. Proceedings of the National Academy of Sciences of the United States of America, 107(39): 16794-16799. doi: 10.1073/pnas. 1012021107

Guo Xianguang, 1998. Improved entropy method and its application in economic benefit evaluation. Systems Engineering-Theory \& Practice, (12): 99-103. (in Chinese)

Ho C H, Yagi N, Tian Y J, 2020. An impact and adaptation assessment of changing coastal fishing grounds and fishery industry under global change. Mitigation and Adaptation Strategies for Global Change, 25(6): 1073-1102. doi: 10.1007/ s11027-020-09922-5

$\mathrm{Hu}$ Guosong, 1980. Utilization of world marine fishery resources. Hebei Fisheries Science and Technology, 2: 58-60. (in Chinese)

Huang Yue, Fang Yangang, Gu Guofeng et al., 2018. The evolution and differentiation of economic convergence of resourcebased cities in Northeast China. Chinese Geographical Science, 28(3): 495-504. doi: 10.1007/s11769-018-0962-6

Huo Zhihui, Wang Zeyu, Fan Yuanxing, 2020. Comprehensive benefit evaluation of China's marine fisheries and research on coupled and coordinated development. Resource Development \& Market, 36(5): 486-493. (in Chinese)

Keithly W R, Roberts K J, 2017. Commercial and recreational fisheries of the gulf of Mexico In:ward $\mathrm{CH}$ (ed). Habitats and Biota of the Gulf of Mexico:Before the Deepwater Horizon Oil Spill. New York:Springer, 1039-1188. doi: 10.1007/978-14939-3456-0_2

Koning A A, Perales K M, Fluet-Chouinard E et al., 2020. A network of grassroots reserves protects tropical river fish diversity. Nature, 588(7839): 631-635. doi: 10.1038/s41586-0202944-y

Li Bo, Jin Xiaoming, Yang Jun et al., 2019. Spatial-temporal evolution and influencing factors of vulnerability of Marine fishery ecosystem in the Bohai Rim Region. Acta Ecologica Sinica, 39(12): 4273-4283. (in Chinese)

Li Bo, Shi Zhaoyuan, Tian Chuang, 2018. Spatio-temporal difference and influencing factors of environmental adaptability measurement of human-sea economic system in Liaoning coastal area. Chinese Geographical Science, 28(2): 313-324. doi: 10.1007/s11769-018-0948-4

Li Dahai, Han Limin, 2019. Research on land and sea coordination to build a new food security system. Journal of Social Sciences, 6: 109-117. (in Chinese)

Li Mengxin, Ren Baoping, 2019. Comprehensive evaluation and path selection of China's high-quality development in the new era. Finance and Economics Science, (5): 26-40. (in Chinese)

Liu Kang, 2003. Development of recreational fishery and optimization of fishery structure: strategic thinking on sustainable development of Qingdao Marine fishery. Ocean Development and Management, (4): 45-49. (in Chinese)

Liu Tao, LI Jixia, HUO Jingjuan, 2020. Spatial-temporal pattern and influencing factors of high-quality agricultural development in China. Journal of arid land resources and environment, 34(10): 1-8. (in Chinese)

Liu Yang, Pei Zhaobin, Jiang Yiying, 2017. The construction of 'Blue Granary' in new normal. Ocean Development and Management, 34(12): 3-8. (in Chinese)

National Bureau of Statistics and Ministry of Environmental Protection, 2001-2017. China Environment Statistical Yearbook (2000-2016). Beijing: China Statistics Press. (in Chinese)

Pauly D, Watson R, Alder J, 2005. Global trends in world fisheries: impacts on marine ecosystems and food security. Philosophical Transactions of the Royal Society B:Biological Sciences, 360(1453): 5-12. doi: 10.1098/rstb.2004.1574

Qiao Jiajun, 2004. Application of improved entropy method in sustainable development capacity assessment of Henan Province. Resources Science, (01): 113-119. (in Chinese)

Ren Baoping, Jiang Jie, Guo Han, 2017. Beyond Quantity: the Paradigm and Standard of Economics of Quality. Beijing: People's Publishing House. (in Chinese)

Rosa R, Vaz J, Mota R et al., 2018. Preference for landings' smoothing and risk of collapse in optimal fishery policies: the Ibero-Atlantic sardine fishery. Environmental and Resource Economics, 71(4): 875-895. doi: 10.1007/s10640-017-0187-7

State Oceanic Administration, 2001-2017. China Marine Statistical Yearbook (2001-2016). Beijing: China Ocean Press. (in Chinese)

Sun Huaping, Zhou Gang, Jiang Dan et al., 2019. Research on the development model of marine agriculture based on the 'blue granary'. Environment and Sustainable Development, 44(1): 45-47. (in Chinese)

Sun Jiting, 2003. Study on Sustainable Development of Marine Fishery of China. Qingdao:Ocean University of China, 2003. (in Chinese)

Tang Qisheng, 2008. Implementing the scientific development concept and actively promoting modern fishery construction: implementing the Blue Ocean Food Development Plan. Chinese Fisheries Economics Expert Forum Proceedings, 4. (in Chinese)

Taylor S F W, Roberts M J, Milligan B et al. , 2019. Measurement and implications of marine food security in the Western Indian Ocean: an impending crisis? Food Security, 11(6): 1395-1415. doi: 10.1007/s12571-019-00971-6

Tong Chunfen, Xia Fei, 2017. Problems and solutions in China's Marine Fishery Against the Background of the Supply-side Reform, Journal of Ocean University of China (Social Sciences), 2017(05): 26-29.

Wang Bo, Ni Guohong, Han Limin, 2019. Impact of the evolution of industry structure on the economic fluctuation of marine fishery. Resources Science, 41(2): 289-300. (in Chinese)

Xu Jingjun, Qin Tiantian, Han Limin, 2018. A review of research on marine carbon sink fisheries. Resources Science, 40(1): 161-172. (in Chinese) 
Yan Yuke, 2009. Research on the sustainable utilization of marine fishery resources in China: analysis on the marine fishery resource decline from the view of economics. Issues in Agricultural Economy, (8): 100-104. (in Chinese)

Yang Chaoguang, 2018. Grasping the priorities of building a maritime power and promoting the high-quality development of marine economy. People's Daily, 2018-07-01. (in Chinese)

Yang Hongsheng, 2019. Development ideas and implementation approaches of blue granary scientific and technological innovation in China. Journal of Fisheries of China, 43(1): 97-104. (in Chinese)

Yang Jiming, 1980. Estimation of the development potential of marine fishery resources. Ocean Development and Management, (4): 40-46. (in Chinese)

Yang Xiaoming, Dai Xiaojie, Tian Siquan et al., 2014. Hot spot analysis and spatial heterogeneity of skipjack tuna (Katsuwonus pelamis) purse seine resources in the western and central Pacific Ocean. Acta Ecologica Sinica, 34(13): 3771-3778. (in Chinese)

Yao Cheng-sheng, Yin Wei, Li Zheng-tong, 2019. Vulnerability assessment and driving mechanism analysis of China's food security system. Journal of natural resources, 34(8): 1720-1734. (in Chinese). doi: 10.31497/zrzyxb.20190812

Yu Huijuan, Niu Min, Han Limin, 2019. Development strategy and industrial Chain reconstruction of 'Blue Food System' in China: an analysis based on food consumption demand upgrading. Issues in Agricultural Economy, (11): 72-81. (in Chinese)

Zhai Lu, Liu Kang, Han Limin, 2019. Current situation, problems and countermeasures of related industries of 'Marine Food System' in China. Ocean Development and Management, 36(1): 91-97. (in Chinese)

Zhang Xiumei, Wang Xijie, Tu Zhong et al., 2009. Current status and prospect of fisheries resource enhancement in Shandong Province. China Fishery Economics, 27(2): 51-58. (in Chinese)

Zhang Yaoguang, Liu Kai, Wang Shengyun, 2006. Research on spatial-temporal characteristics of Marine economic regional system in China. Progress in Geography, (5): 47-56+133. (in Chinese) 